\title{
INSTRUMENTOS PARA AVALIAR DISCIPLINAS DA MODALIDADE SEMIPRESENCIAL: UMA PROPOSTA BASEADA EM SISTEMAS DE INDICADORES
}

\author{
Júlio C. G. Bertolin* \\ ana Carolina Bertoletti De Marchi**
}

Recebido em: 23 de março de $2010 \quad$ Aprovado em: 22 de junho de 2010

* Dr. em Educação pela Universidade Federal do Rio Grande do Sul (UFRGS), professor da Universidade de Passo Fundo (UPF). Foi membro da Comissão Especial de Avaliação (CEA) do MEC, que elaborou a proposta original do SINAES. E-mail: julio@upf.br

** Dra. em Informática na Educação pela Universidade Federal do Rio Grande do Sul (UFRGS), professora da Universidade de Passo Fundo (UPF). Coordenadora da Divisão UPF Virtual. E-mail: carolina@upf.br

Resumo: A avaliação da educação é um tema complexo e que possui grande importância nas abordagens e projetos de qualidade de instituições, cursos e disciplinas da educação superior. Quando abordada no âmbito da educação a distância $(\mathrm{EaD})$, a avaliação da qualidade da educação adquire uma relevância e complexidade ainda maiores visto que as diferenças de espaço e tempo entre professor e aluno certamente impactam o processo de aprendizagem. O presente artigo busca contribuir com a avaliação da qualidade da modalidade $\mathrm{EaD}$ por meio do desenvolvimento de uma proposta de instrumentos para avaliação de disciplinas semipresenciais da educação superior. Fundamentado em sistemas de indicadores e composto por questionários de avaliação e auto-avaliação, o instrumento incorpora aspectos de auto-validação ao permitir o cotejamento entre os indicadores de resultados e os aspectos de entradas e processo da disciplina e entre a avaliação de um sujeito interessado e a auto-avaliação de outros sujeitos envolvidos.

Palavras-chave: Avaliação. Educação a distância. Avaliação de disciplina semipresencial.

\section{INSTRUMENTS FOR THE EVALUATION OF SEMIPRESENTIAL COURSES: A PROPOSAL BASED ON SYSTEMS OF INDICATORS}

\begin{abstract}
The evaluation of education is a complex issue that has great importance in approaches and projects for quality in higher education institutions, programs and courses. When approached in the context of distance education (D.Ed.), the evaluation of the quality of education takes on even greater relevance and complexity because differences in space and time between teacher and student will certainly impact the learning process. This article intends to contribute to the evaluation of the quality of Distance Education through the development of a proposal of instruments to evaluate hybrid courses in higher education. Based on systems of indicators and composed by evaluation and self-evaluation questionnaires, the instrument incorporates aspects of self validation by allowing the collation between the indicators of results and the aspects of inputs and process of the course and between the evaluation of a person involved with the course and the self-evaluation of other people involved.
\end{abstract}

Key words: Evaluation. Distance education. Hybrid courses. Evaluation of hybrid disciplines.

\section{INTRODUÇÃO}

A avaliação da educação é um tema complexo que possui importância significativa nas abordagens e projetos de qualidade de instituições e cursos superiores. Da mesma forma que existem diferentes visões de educação superior 
e de qualidade em educação, também existem diferentes concepções e formas de operacionalizar a avaliação da educação. Nas últimas duas décadas, debates acerca da avaliação da educação superior adquiriram grande proeminência, envolvendo profissionais e pesquisadores de diferentes áreas do conhecimento. Entretanto, no âmbito da emergente modalidade de $\mathrm{EaD}$ os estudos e trabalhos de avaliação ainda são incipientes. Quando abordada no âmbito da modalidade à distância, a avaliação da qualidade da educação adquire maior complexidade e importância visto que as diferenças de espaço e tempo entre professor e aluno podem impactar qualitativamente o processo de aprendizagem.

Alguns autores questionam a própria possibilidade da modalidade EaD possuir qualidade e proporcionar uma efetiva aprendizagem para os alunos. Por outro lado, pesquisas recentes têm apontado que a modalidade EaD pode alcançar níveis de qualidade equivalentes ou superiores a modalidade presencial (INEP/MEC, 2009). Paralelamente a esse debate, à modalidade a distância tem experimentado uma grande expansão em todo o mundo. No Brasil, entre os anos 2003 e 2006, ocorreu um aumento de 571\% no número de cursos e $315 \%$ no número de matriculas na educação a distância. Em 2005 o universo de estudantes da EaD representavam 2,6\%, já em 2006 essa participação passou a ser de 4,4\%. (ABRAEAD, 2008).

Concomitantemente ao desenvolvimento da EaD no Brasil, o Ministério da Educação autorizou em 2004, por meio da Portaria 4.059, a implementação da semipresencialidade em instituições de educação superior. As disciplinas semipresenciais ocorrem exclusivamente em cursos de graduação presenciais que podem desenvolver até $20 \%$ do total da sua carga horária na modalidade a distância. Dentro do escopo de uma disciplina, a modalidade a distância pode ser desenvolvida integral ou parcialmente, resguardadas as avaliações que devem ser presenciais. Dessa forma, uma disciplina semipresencial tem como característica marcante o desenvolvimento da modalidade $\mathrm{EaD}$ num contexto de predominância de aulas e atividades presenciais.

Assim como em cursos EaD, as disciplinas semipresenciais também flexibilizam o processo de aprendizagem em relação ao tempo e ao espaço. Portanto, a semipresencialidade pode agregar ganhos na formação para os alunos de cursos presenciais, tais como: (i) o desenvolvimento da autonomia e da autoorganização, visto que as atividades EaD demandam tais comportamentos e (ii) o desenvolvimento de habilidades no uso das TIC, que são ferramentas necessárias para um adequado acompanhamento dos conteúdos à distância. Nessa perspectiva, a oferta de disciplinas semipresenciais num curso de graduação pode ser de grande relevância, visto que possibilitam a complementação da formação do 
aluno pelo aprimoramento do perfil comportamental e das habilidades no uso de ferramentas tecnológicas importantes para o profissional contemporâneo.

Nos últimos anos, pesquisas sobre a qualidade da educação a distância estão sendo realizadas. Em seus estudos Valcheva e Todorova (2005) citaram algumas das abordagens mais implementadas para a avaliação dessa modalidade, são elas: (i) comparação com a aprendizagem tradicional: nessa abordagem é estudada a comparação da efetividade da educação a distância com a aprendizagem presencial, por meio de indicadores de qualidade determinados preliminarmente; (ii) ferramentas e instrumentos para avaliação da educação a distância: são instrumentos de avaliação utilizados, tipicamente, para identificar a percepção dos usuários através de suas repostas em questionários ou dispositivos para armazenar e analisar a duração e a frequência de login, páginas acessadas, etc.; (iii) comparação com um sistema hipotético: que contenha um conjunto de requerimentos e funções relevantes. Essa abordagem é difícil de ser implementada, pois não há características exatas para um sistema hipotético e cada usuário terá sua própria concepção de sistema ideal; (iv) indicadores de avaliação: utilizados para avaliar a plataforma de educação a distância como, também, para propor características necessárias ao desenvolvimento de novos ambientes.

Diante do contexto acima descrito, é possível perceber que as pesquisas avaliativas da educação a distância estão centradas ora na comparação com a educação presencial, com ênfase nos aspectos de resultados; ora nas plataformas/ambientes de aprendizagem virtual, com ênfase no processo. Ou seja, as avaliações de $\mathrm{EaD}$ desenvolvidas até o momento não abordam todos os aspectos do desenvolvimento da modalidade, isto é, entradas, processo e resultados.

Nesse sentido, o presente artigo busca contribuir com a avaliação da qualidade da modalidade $\mathrm{EaD}$ por meio do desenvolvimento de uma proposta de instrumento para avaliação de disciplinas semipresenciais de educação superior. Para embasar tal proposta são considerados como referenciais teóricos os indicadores de sistema e as características especificas da modalidade $\mathrm{EaD}$ e da semipresencialidade.

\section{SISTEMAS DE INDICADORES}

Nos últimos tempos, organismos internacionais como a Unesco e a OCDE e também alguns pesquisadores têm interpretado uma concepção de qualidade em educação por meio da representação de sistemas de indicadores. Ainda em 1966, Cheng (apud SAHNEY; BANWET; KARUNES, 2004) definiu qualidade educacional como "as características de um conjunto de elementos na 
entrada, processo, e saída do sistema educacional que proporcionam serviços que satisfazem completamente estratégias dos envolvidos internos e externos, contemplando suas implícitas e explícitas expectativas". Da mesma forma, para Estrada (1999), a avaliação da qualidade em educação se "expressa como um juízo de valor sobre um atributo ou um conjunto de atributos acerca dos insumos [ou entradas], processos, resultados ou produtos educativos, ou das relações entre eles".

O entendimento conceitual do Laboratorio Latinoamericano de Evaluación de la Calidad de la Educación da Unesco (UNESCO, 1997) também se reporta a indicadores sistêmicos ao afirmar que a qualidade em educação possui "estreita relação com o nível de êxito dos objetivos educacionais, no marco dos programas oficiais de estudo, levando em conta as variáveis de insumo [ou entradas] e especialmente processo". O conceito subjacente do órgão determina que:

o nível de qualidade da educação consiste basicamente na definição de um conjunto de variáveis que proporcione, em forma sistemática, um quadro confiável e válido acerca do estado dos sistemas de educação e que pode ser utilizado para colaborar na orientação e ações de melhoria. (UNESCO, 1997, p. 7)

De acordo com García (2000), os sistemas de indicadores procuram superar a obtenção de uma simples soma de dados ao agrupar indicadores simples ou compostos em função de fatores e aspectos que lhes deêm sentido e uma visão significativa do estado dos sistemas de educação.

As experiências de avaliação vinculadas à avaliação com sistemas de indicadores consideram que a qualidade em educação é um conceito múltiplo que não pode ser avaliado por apenas um aspecto isolado e deve envolver todos os elementos fundamentais do sistema ou processo. Assim, pode-se dizer que é possível avaliar a qualidade em educação por meio de juízo de valor sobre um conjunto de atributos, aspectos ou indicadores acerca das entradas, processo e resultados ${ }^{1}$ educativos, ou das relações entre eles.

Geralmente, os indicadores de entradas referem-se aos recursos, tanto financeiros como humanos e tecnológicos, que se destinam à educação. Aspectos relativos aos custos gerais, aos investimentos em TIC e a quantidade e formação dos docentes também podem estar incluídos entre os indicadores de entrada e/

1 Existe certa variedade de denominações para representar os indicadores relacionados aos propósitos dos sistemas de educação, tais como "produtos", "resultados" ou "saídas" dos sistemas. Neste estudo é adotada, predominantemente, a denominação de "indicadores de resultados" para todos os aspectos relativos aos mais diversos propósitos de um sistema de educação. 
ou recursos. Os indicadores de processo referem-se ao contexto pedagógico e organizacional, ou seja, dizem respeito às características primárias, relativas à participação direta do processo de educação, e secundárias, relativas ao apoio à organização das características primárias. Aspectos relativos ao número de horas de ensino, dedicação dos docentes, acesso e utilização das TIC podem compor a estrutura dos indicadores de processo. Os indicadores de resultados referem-se às características relativas aos propósitos intermediários e últimos da educação; nível de êxito dos alunos em exames, proporção de aprovados e taxas de escolarização podem estar entre os indicadores de resultados (ESTRADA, 1999), (EC, 2001), (OECD , 2002) e (NAVARA, 2004).

Tabela 1. Estrutura básica do sistema de indicadores para a educação superior

\begin{tabular}{l|l}
\hline $\begin{array}{l}\text { Aspectos } \\
\text { de entradas }\end{array}$ & $\begin{array}{l}\text { Custos e recursos, investimento com tecnologia de informações e quanti- } \\
\text { dade e formação dos docentes. }\end{array}$ \\
\hline $\begin{array}{l}\text { Aspectos } \\
\text { de processo }\end{array}$ & $\begin{array}{l}\text { Contexto pedagógico e organizacional ou características primárias, } \\
\text { relativas à participação direta do processo de educação, e secundárias, } \\
\text { relativas ao apoio à organização das características primárias. }\end{array}$ \\
\hline $\begin{array}{l}\text { Aspectos } \\
\text { de resultados }\end{array}$ & $\begin{array}{l}\text { Características relativas aos propósitos intermediários e últimos da educa- } \\
\text { ção. }\end{array}$ \\
\hline
\end{tabular}

Fonte: Adaptado de (BERTOLIN, 2007).

Não obstante a existência e a possibilidade de outras formas de organização, os sistemas de indicadores estruturados sistemicamente (Tabela 1) tornaram-se um dos métodos mais empregados para avaliar a qualidade em educação superior, principalmente, em nível de sistema. Ainda não existe um consenso geral sobre a quantidade necessária, tampouco sobre os aspectos mais apropriados para comporem um sistema de indicadores, entretanto está claro que a existência de elementos de entradas, de processo e de resultados do objeto de análise é fundamental. Não obstante uma maior aplicação em avaliações de sistemas de educação, tal estrutura pode ser empregada para avaliação de uma instituição, um curso ou mesmo uma disciplina visto que, segundo Fatma Mizikaci (2006), um sistema é um conjunto de elementos interdependentes e interagentes; um grupo de unidades combinadas que formam um todo organizado e cujo resultado é maior do que o resultado que as unidades poderiam ter se funcionassem de forma independente. Assim como as instituições podem ser consideradas 
elementos de um sistema de educação, cursos podem ser considerados unidades do sistema instituição, disciplinas unidades do sistema cursos e, por conseguinte, os elementos constitutivos as unidades do sistema disciplina.

Desta forma, em face dos objetivos deste artigo, pressupõe-se que a avaliação da qualidade de disciplinas semipresenciais está diretamente relacionada ao acompanhamento de desempenho de um conjunto de indicadores de entradas, de processos e de resultados.

\section{DEFININDO INDICADORES PARA SEMIPRESENCIALIDADE}

A semipresencialidade vem se consolidando, passo a passo, como uma alternativa pedagógica importante para potencializar o processo de formação profissional, aproximando os alunos dos recursos tecnológicos indispensáveis no mundo do trabalho contemporâneo. A responsabilidade agregada às atividades não-presenciais está fundamentada, especialmente, em seis princípios (DE MARCHI; ARAÚJO; STREIT, 2008). São eles:

- interação e aprendizado colaborativo: permite a construção do conhecimento pelo viés do diálogo e da troca constante de saberes junto aos colegas e professores, que superam a distância física e temporal nas relações interpessoais, tendo em vista o compromisso assumido com o desenvolvimento intelectual, cultural e humano dos sujeitos envolvidos no processo educativo;

- autonomia na aprendizagem: contribui para a formação de um sujeito comprometido com o estudo, responsável pela organização de seu tempo na busca contínua do aprender. O aluno deve assumir sua autonomia, envolvendo-se numa rede de relacionamentos que favoreça o desenvolvimento cognitivo de todo o grupo;

- flexibilização do tempo e do espaço: possibilita a realização das atividades da disciplina em horário e local mais apropriado ao acadêmico, em especial àquele já inserido no mercado de trabalho, reduzindo as horas de deslocamento até a instituição e possibilitando o cumprimento das atividades, de acordo com a necessidade e característica de cada aluno;

- potencialização do uso das ferramentas tecnológicas na educação: considera as Tecnologias de Informação e Comunicação a serviço do processo de ensinar e aprender à distância, fomentando a apropriação das mesmas em prol da formação humana e profissional, uma vez que o aluno incorpora 
tal instrumental ao seu cotidiano em busca do cumprimento dos objetivos da disciplina;

- qualidade dos materiais e da metodologia: prevê um processo cuidadoso nas fases de planejamento, desenvolvimento, implantação e avaliação dos materiais a serem adotados nas disciplinas ou unidades curriculares, considerando, ainda, a realidade dos acadêmicos e o atendimento de suas necessidades;

- apoio e suporte: mantém estrutura de apoio técnico e pedagógico ao acadêmico, objetivando a interação permanente com o estudante, o esclarecimento de suas dúvidas e o incentivo para a continuidade dos estudos, de forma a fortalecer o engajamento do aluno com o curso.

As disciplinas semipresenciais vêm ao encontro dos interesses e das necessidades dos cursos de graduação, uma vez que a utilização de métodos e de ferramentas vinculadas à educação a distância possibilita aos acadêmicos a aproximação e a apropriação no uso das tecnologias de informação e comunicação. Além disso, qualifica a formação profissional por incentivar o espírito de investigação, a interação e a colaboração nas relações acadêmicas e na construção do conhecimento.

A modalidade semipresencial é uma proposta que reflete uma tendência educacional nas instituições de educação superior do país e uma aposta na ampliação das possibilidades de interação no fazer pedagógico. $\mathrm{O}$ aperfeiçoamento desta modalidade nos cursos de graduação está vinculado à constante reflexão acerca de tal iniciativa com participação da (i) própria instituição; (ii) dos docentes e (iii) dos discentes, demandado, portanto, pesquisas e avaliações acerca da qualidade da modalidade como um todo.

Desta forma, a avaliação da qualidade de disciplinas semipresenciais deve ser desenvolvida com a participação de todos os sujeitos interessados, por meio de instrumentos constituídos por indicadores sistêmicos que expressam as especificidades e particularidades da modalidade semipresencial.

Nesse sentido, como indicadores de entrada para a avaliação de uma disciplina semipresencial podem ser considerados:

- a qualidade da infraestrutura, onde se destacam: (i) o ambiente virtual de aprendizagem, que ocupa papel fundamental nos momentos à distância como espaço social de interações; (ii) os recursos de bidirecionalidade, para comunicação e interação professor-aluno-tutor, como a videoconferência e (iii) os laboratórios de informática, que podem ser utilizados 
pelos alunos para as atividades práticas e acompanhamento da disciplina, caso os alunos não disponham de acesso à internet fora da universidade;

- as habilidades e competências do professor e dos tutores para atuarem nas disciplinas semipresencias, onde se destaca a formação e/ou experiência prévia em Educação a Distância;

- as habilidades prévias dos alunos no uso das TIC, que podem potencializar ou dificultar o acompanhamento da disciplina semipresencial;

- a qualidade do planejamento da disciplina, onde se destacam: (i) o plano de ensino; (ii) a adequação do percentual de aulas à distância em relação aos conteúdos previstos; (iii) a preparação prévia do material didático e das demais mídias a serem empregadas; (iv) a indicação de bibliografias pertinentes e atualizadas.

Em relação aos aspectos de processo podem ser considerados como indicadores os seguintes parâmetros:

- a eficácia da dinâmica de interação imprimida entre professor-tutor-aluno, que permite identificar o nível de colaboração entre os sujeitos envolvidos na disciplina;

- a efetividade da tutoria aos alunos, no que se refere ao acompanhamento dos mesmos quanto às tarefas solicitadas; esclarecimentos de dúvidas e o contato sistemático;

- a efetividade do suporte aos alunos, para auxiliar nas questões técnicas;

- a efetividade na articulação entre momentos presenciais e a distância, onde se destaca, principalmente, a adequada integração entre os diferentes momentos por parte do professor, considerando os conteúdos previstos;

- a qualidade da prática didático-pedagógica do professor nos momentos presenciais, que possibilita identificar se o conteúdo é exposto em uma linguagem de fácil compreensão;

- a efetiva flexibilização da aprendizagem no tempo e no espaço pelos alunos, levando em consideração que o aluno não precisa estar fisicamente presente e que as atividades podem ser realizadas ao longo de períodos mais extensos;

- a eficácia na avaliação da aprendizagem, para permite identificar se o professor é adequadamente exigente e se propõe práticas avaliativas que valorizam a reflexão. 
Por fim, como aspectos de resultados a serem considerados como objetivos alcançados, este trabalho propõe os seguintes indicadores:

- a efetiva aprendizagem (rendimento) dos alunos, percebendo se o aproveitamento do conteúdo nos momentos a distância foi equivalente às aulas presenciais;

- a efetiva aquisição de habilidades no uso das TIC pelos alunos, procurando identificar se a experiência da semipresencialidade foi importante para a sua aproximação com as ferramentas computacionais;

- o efetivo desenvolvimento do comportamento de autonomia e disciplina nos alunos, onde se destacam: (i) a iniciativa do aluno em suprir dificuldades quanto ao conteúdo e à utilização do ambiente virtual de aprendizagem e (ii) a organização do tempo adequadamente para cumprir as atividades a distância.

Assim, após a observância e embasamento no conceito de qualidade baseado em indicadores sistêmicos se obtêm o sistema de indicadores representado na Tabela 2, com vistas a avaliar a qualidade de disciplinas semipresenciais.

Tabela 2. Indicadores para disciplinas semipresenciais

\begin{tabular}{|c|c|}
\hline \multirow{4}{*}{ Entradas } & $\begin{array}{l}\text { E1- Qualidade da infraestrutura: ambiente virtual de aprendizagem, videoconfe- } \\
\text { rência, laboratórios etc. }\end{array}$ \\
\hline & E2- Habilidades e competências do professor e dos tutores \\
\hline & E3- Habilidades prévias dos alunos no uso das TIC. \\
\hline & $\begin{array}{l}\text { E4- Qualidade do planejamento da disciplina: plano de ensino, c/h EaD, material } \\
\text { didático, bibliografia, mídias etc. }\end{array}$ \\
\hline \multirow{7}{*}{ Processo } & P1- Eficácia da dinâmica de interação imprimida entre professor-tutor-aluno \\
\hline & P2- Efetividade da tutoria aos alunos \\
\hline & P3- Efetividade do suporte aos alunos \\
\hline & $\begin{array}{l}\text { P4- Efetividade na articulação entre momentos presenciais e à distância: conteú- } \\
\text { dos e carga-horária }\end{array}$ \\
\hline & $\begin{array}{l}\text { P5- Qualidade da prática didático-pedagógica do professor em momentos pre- } \\
\text { senciais }\end{array}$ \\
\hline & P6- Efetiva flexibilização da aprendizagem no tempo e no espaço pelos alunos \\
\hline & P7- Eficácia na avaliação da aprendizagem \\
\hline \multirow{3}{*}{ Resultados } & R1- Efetiva aprendizagem (rendimento) dos alunos \\
\hline & R2- Efetiva aquisição de habilidades no uso das TIC pelos alunos \\
\hline & $\begin{array}{l}\text { R3- Efetivo desenvolvimento do comportamento de autonomia e disciplina pelos } \\
\text { alunos }\end{array}$ \\
\hline
\end{tabular}


Nessa disposição em aspectos de entradas, de processo e resultados os indicadores não se limitam a verificar se os objetivos e as metas (por exemplo, de aprendizagem) foram alcançados. Ao abordarem as questões das entradas e do processo, que têm importância fundamental na aprendizagem, podem ser explicadas muitas das causas dos resultados obtidos numa disciplina semipresencial e, por conseguinte, possibilitar a emissão de um juízo de valor mais confiável sobre a qualidade dessas disciplinas.

\section{PROPOSTA DE INSTRUMENTOS PARA AVALIAR DISCIPLINAS SEMIPRESENCIAIS}

No desenvolvimento de uma disciplina semipresencial os principais envolvidos são o professor, os alunos e o pessoal de suporte as atividades à distância (tutores, projetistas etc.). Portanto, para que a avaliação de uma disciplina semipresencial seja completa e confiável é importante a participação de todos esses sujeitos interessados na qualidade e no bom desempenho do processo de aprendizagem.

Neste sentido, questionários específicos, para os diferentes sujeitos são necessários com vistas a cobrir todos os aspectos (indicadores) a serem avaliados e possibilitar a auto-validação da própria avaliação. Tal verificação pode ser desenvolvida por meio do cotejamento entre as respostas dos sujeitos que se auto-avaliam e as respostas de outros sujeitos envolvidos que avaliam um determinado aspecto. Quanto maior a similaridade de respostas entre autoavaliador e avaliador, maior o nível de confiabilidade da avaliação realizada. Os diferentes sujeitos desempenham diferentes papéis (de avaliador ou de autoavaliador) conforme as suas funções de protagonistas ou de utente em relação a cada indicador.

A seguir é apresentada a relação dos papéis desempenhados pelos diferentes sujeitos como avaliadores ou autoavaliadores para cada um dos indicadores propostos.

A partir da relação de papéis de avaliador ou autoavaliador estabelecida para os sujeitos na tabela a seguir é possível definir os questionários específicos para professor, alunos e pessoal de suporte. A seguir, são apresentados os instrumentos a serem respondidos pelos sujeitos envolvidos e interessados na avaliação de uma disciplina semipresencial. 
Tabela 3. Instrumento geral de avaliação de disciplina semipresencial

\begin{tabular}{|c|c|c|}
\hline \multirow{4}{*}{ Entradas } & $\begin{array}{l}\text { E1- Qualidade da infraestrutura: ambiente } \\
\text { virtual de aprendizagem, videoconferência, } \\
\text { laboratórios etc. }\end{array}$ & $\begin{array}{l}\text { (1) Aluno } \rightarrow \text { avaliador } \\
\text { (2) Professor } \rightarrow \text { avaliador } \\
\text { (3) Pessoal de suporte } \rightarrow \text { autoa- } \\
\text { valiador }\end{array}$ \\
\hline & $\begin{array}{l}\text { E2- Habilidades e competências do profes- } \\
\text { sor e dos tutores }\end{array}$ & $\begin{array}{l}\text { (1) Aluno } \rightarrow \text { avaliador } \\
\text { (2) Professor } \rightarrow \text { autoavaliador } \\
\text { (3) Pessoal de suporte } \rightarrow \text { autoa- } \\
\text { valiador }\end{array}$ \\
\hline & $\begin{array}{l}\text { E3- Habilidades prévias dos alunos no uso } \\
\text { das TIC. }\end{array}$ & $\begin{array}{l}\text { (1) Aluno } \rightarrow \text { autoavaliador } \\
\text { (3) Pessoal de suporte } \rightarrow \text { ava- } \\
\text { liador }\end{array}$ \\
\hline & $\begin{array}{l}\text { E4- Qualidade do planejamento da disciplina: } \\
\text { plano de ensino, c/h EaD, material didático, } \\
\text { bibliografia, mídias etc. }\end{array}$ & $\begin{array}{l}\text { (1) Aluno } \rightarrow \text { avaliador } \\
\text { (2) Professor } \rightarrow \text { autoavaliador } \\
\text { (3) Pessoal de suporte } \rightarrow \text { autoa- } \\
\text { valiador }\end{array}$ \\
\hline \multirow{7}{*}{ Processo } & $\begin{array}{l}\text { P1- Eficácia da dinâmica de interação impri- } \\
\text { mida entre professor-tutor-aluno }\end{array}$ & $\begin{array}{l}\text { (1) Aluno } \rightarrow \text { avaliador } \\
(2) \text { Professor } \rightarrow \text { autoavaliador } \\
\text { (3) Pessoal de suporte } \rightarrow \text { autoa- } \\
\text { valiador }\end{array}$ \\
\hline & P2- Efetividade da tutoria aos alunos & $\begin{array}{l}\text { (1) Aluno } \rightarrow \text { avaliador } \\
\text { (2) Professor } \rightarrow \text { avaliador } \\
\text { (3) Pessoal de suporte } \rightarrow \text { autoa- } \\
\text { valiador }\end{array}$ \\
\hline & P3- Efetividade do suporte aos alunos & $\begin{array}{l}\text { (1) Aluno } \rightarrow \text { avaliador } \\
\text { (2) Professor } \rightarrow \text { avaliador } \\
\text { (3) Pessoal de suporte } \rightarrow \text { autoa- } \\
\text { valiador }\end{array}$ \\
\hline & $\begin{array}{l}\text { P4- Efetividade na articulação entre mo- } \\
\text { mentos presenciais e à distância: conteú- } \\
\text { dos e carga-horária }\end{array}$ & $\begin{array}{l}\text { (1) Aluno } \rightarrow \text { avaliar } \\
\text { (2) Professor } \rightarrow \text { autoavaliador }\end{array}$ \\
\hline & $\begin{array}{l}\text { P5- Qualidade da prática didático-pedagó- } \\
\text { gica do professor em momentos presen- } \\
\text { ciais }\end{array}$ & $\begin{array}{l}\text { (1) Aluno } \rightarrow \text { avaliar } \\
\text { (2) Professor } \rightarrow \text { autoavaliador }\end{array}$ \\
\hline & $\begin{array}{l}\text { P6- Efetiva flexibilização da aprendizagem } \\
\text { no tempo e no espaço pelos alunos }\end{array}$ & $\begin{array}{l}\text { (1) Aluno } \rightarrow \text { autoavaliador } \\
(2) \text { Professor } \rightarrow \text { avaliador } \\
\text { (3) Pessoal de suporte } \rightarrow \text { ava- } \\
\text { liador }\end{array}$ \\
\hline & P7- Eficácia na avaliação da aprendizagem & $\begin{array}{l}\text { (1) Aluno } \rightarrow \text { avaliador } \\
\text { (2) Professor } \rightarrow \text { autoavaliador }\end{array}$ \\
\hline \multirow{3}{*}{ Resultados } & $\begin{array}{l}\text { R1- Efetiva aprendizagem (rendimento) } \\
\text { dos alunos }\end{array}$ & $\begin{array}{l}\text { (1) Aluno } \rightarrow \text { autoavaliador } \\
\text { (2) Professor } \rightarrow \text { avaliador }\end{array}$ \\
\hline & $\begin{array}{l}\text { R2- Efetiva aquisição de habilidades no uso } \\
\text { das TIC pelos alunos }\end{array}$ & $\begin{array}{l}\text { (1) Aluno } \rightarrow \text { autoavaliador } \\
\text { (2) Professor } \rightarrow \text { avaliador }\end{array}$ \\
\hline & $\begin{array}{l}\text { R3- Efetivo desenvolvimento do compor- } \\
\text { tamento de autonomia e disciplina pelos } \\
\text { alunos }\end{array}$ & $\begin{array}{l}\text { (1) Aluno } \rightarrow \text { autoavaliador } \\
\text { (2) Professor } \rightarrow \text { avaliador }\end{array}$ \\
\hline
\end{tabular}


Tabela 4. Instrumento para Alunos

\begin{tabular}{|c|c|c|}
\hline \multirow{4}{*}{ Entradas } & $\begin{array}{l}\text { EA1- A infra-estrutura de EaD (ambiente/software de } \\
\text { aprendizagem, recursos de videoconferência etc.) } \\
\text { disponibilizada pela instituição para a disciplina pode } \\
\text { ser avaliada como? }\end{array}$ & $\begin{array}{l}\text { (5) ótima, (4) boa, } \\
\text { (3) regular, (2) ruim, } \\
\text { (1) péssima }\end{array}$ \\
\hline & $\begin{array}{l}\text { EA2- As habilidades e competências do professor e } \\
\text { dos tutores para desenvolvimento da disciplina semi- } \\
\text { presencial podem ser avaliadas como? }\end{array}$ & $\begin{array}{l}\text { (5) ótimas, (4) boas, } \\
\text { (3) regulares, (2) ruins } \\
\text { (1) péssimas }\end{array}$ \\
\hline & $\begin{array}{l}\text { EA3- As suas habilidades de uso de computador an- } \\
\text { tes do início da disciplina podem ser avaliadas como? }\end{array}$ & $\begin{array}{l}\text { (5) ótimas, (4) boas, (3) } \\
\text { regulares, (2) ruins, (1) } \\
\text { péssimas }\end{array}$ \\
\hline & $\begin{array}{l}\text { EA4- O planejamento (plano de ensino, c/h EaD, } \\
\text { material didático, bibliografia, mídias etc.) realizado } \\
\text { pelo(a) professor(a) para a disciplina pode ser avalia- } \\
\text { do como? }\end{array}$ & $\begin{array}{l}\text { (5) ótimo, (4) bom, (3) } \\
\text { regular, (2) ruim, (1) } \\
\text { péssimo }\end{array}$ \\
\hline \multirow{7}{*}{ Processo } & $\begin{array}{l}\text { PA1- A interação dialógica desenvolvida entre } \\
\text { professor-tutor-aluno durante a disciplina pode ser } \\
\text { avaliada como? }\end{array}$ & $\begin{array}{l}\text { (5) ótima, (4) boa, (3) } \\
\text { regular, (2) ruim, (1) } \\
\text { péssima }\end{array}$ \\
\hline & $\begin{array}{l}\text { PA2- A tutoria prestada durante o desenvolvimento da } \\
\text { disciplina pode ser avaliada como? }\end{array}$ & $\begin{array}{l}\text { (5) ótima, (4) boa, (3) } \\
\text { regular, (2) ruim, (1) } \\
\text { péssima }\end{array}$ \\
\hline & $\begin{array}{l}\text { PA3- O suporte técnico prestado durante o desenvol- } \\
\text { vimento da disciplina pode ser avaliado como? }\end{array}$ & $\begin{array}{l}\text { (5) ótimo, (4) bom, (3) } \\
\text { regular, (2) ruim, (1) } \\
\text { péssimo }\end{array}$ \\
\hline & $\begin{array}{l}\text { PA4- A articulação e a adequação entre os momentos } \\
\text { presenciais e à distância (conteúdos e carga-horária) } \\
\text { da disciplina podem ser avaliadas como? }\end{array}$ & $\begin{array}{l}\text { (5) ótima, (4) boa, (3) } \\
\text { regular, (2) ruim, (1) } \\
\text { péssima }\end{array}$ \\
\hline & $\begin{array}{l}\text { PA5- A prática didático-pedagógica desenvolvida } \\
\text { pelo professor em momentos presenciais pode ser } \\
\text { avaliada como? }\end{array}$ & $\begin{array}{l}\text { (5) ótima, 4) boa, (3) } \\
\text { regular, (2) ruim, (1) } \\
\text { péssima }\end{array}$ \\
\hline & $\begin{array}{l}\text { PA6- O nível de flexibilização da sua aprendizagem } \\
\text { em relação ao tempo e ao espaço durante o desenvol- } \\
\text { vimento da disciplina pode ser avaliado como? }\end{array}$ & $\begin{array}{l}\text { (5) ótimo, (4) bom, (3) } \\
\text { regular, (2) ruim. (1) } \\
\text { péssimo }\end{array}$ \\
\hline & $\begin{array}{l}\text { PA7- A avaliação da aprendizagem desenvolvida na } \\
\text { disciplina pode ser avaliada como? }\end{array}$ & $\begin{array}{l}\text { (5) ótima, (4) boa, (3) } \\
\text { regular, (2) ruim, (1) } \\
\text { péssima }\end{array}$ \\
\hline \multirow{3}{*}{ Resultados } & $\begin{array}{l}\text { RA1- A sua aprendizagem e o seu aproveitamento da } \\
\text { disciplina podem ser avaliados como? }\end{array}$ & $\begin{array}{l}\text { (5) ótima, (4) boa, (3) } \\
\text { regular, (2) ruim, (1) } \\
\text { péssima }\end{array}$ \\
\hline & $\begin{array}{l}\text { RA2- O desenvolvimento de suas habilidades no uso } \\
\text { de computador durante o transcorrer da disciplina } \\
\text { pode ser avaliado como? }\end{array}$ & $\begin{array}{l}\text { (5) ótimo, (4) bom, (3) } \\
\text { regular, (2) ruim, (1) } \\
\text { péssimo }\end{array}$ \\
\hline & $\begin{array}{l}\text { RA3- O desenvolvimento da sua capacidade de } \\
\text { autonomia e de auto-organização (tempo) durante o } \\
\text { transcorrer da disciplina pode ser avaliado como? }\end{array}$ & $\begin{array}{l}\text { (5) ótimo, (4) bom, (3) } \\
\text { regular, (2) ruim, (1) } \\
\text { péssimo }\end{array}$ \\
\hline
\end{tabular}


Tabela 5. Instrumento para Professor

\begin{tabular}{|c|c|c|}
\hline \multirow{3}{*}{ Entradas } & $\begin{array}{l}\text { EP1-A infra-estrutura de EaD (ambiente/software de apren- } \\
\text { dizagem, recursos de videoconferência etc.) disponibilizada } \\
\text { pela instituição para a disciplina pode ser avaliada como? }\end{array}$ & $\begin{array}{l}\text { (5) ótima, (4) boa, (3) } \\
\text { regular, (2) ruim, (1) } \\
\text { péssima }\end{array}$ \\
\hline & $\begin{array}{l}\text { EC2- As suas habilidades e competências e dos tutores } \\
\text { para desenvolvimento da disciplina semipresencial podem } \\
\text { ser avaliadas como? }\end{array}$ & $\begin{array}{l}\text { (5) ótimas, (4) boas, } \\
\text { (3) regulares, (2) ruins, } \\
\text { (1) péssimas }\end{array}$ \\
\hline & $\begin{array}{l}\text { EC4- O planejamento (plano de ensino, c/h EaD, material } \\
\text { didático, bibliografia, mídias etc.) realizado por você para } \\
\text { a disciplina pode ser avaliado como? }\end{array}$ & $\begin{array}{l}\text { (5) ótimo, (4) bom, (3) } \\
\text { regular, (2) ruim, (1) } \\
\text { péssimo }\end{array}$ \\
\hline \multirow{7}{*}{ Processo } & $\begin{array}{l}\text { PP1- A interação dialógica desenvolvida entre professor- } \\
\text { tutor-aluno durante a disciplina pode ser avaliada como? }\end{array}$ & $\begin{array}{l}\text { (5) ótima, (4) boa, (3) } \\
\text { regular, (2) ruim, (1) } \\
\text { péssima }\end{array}$ \\
\hline & $\begin{array}{l}\text { PP2- A tutoria prestada aos alunos durante o desenvolvi- } \\
\text { mento da disciplina pode ser avaliada como? }\end{array}$ & $\begin{array}{l}\text { (5) ótima, (4) boa, (3) } \\
\text { regular, (2) ruim, (1) } \\
\text { péssima }\end{array}$ \\
\hline & $\begin{array}{l}\text { PP3- O suporte técnico prestado aos alunos durante o } \\
\text { desenvolvimento da disciplina pode ser avaliado como? }\end{array}$ & $\begin{array}{l}\text { (5) ótimo, (4) bom, (3) } \\
\text { regular, (2) ruim, (1) } \\
\text { péssimo }\end{array}$ \\
\hline & $\begin{array}{l}\text { PP4- A articulação e a adequação entre os momentos } \\
\text { presenciais e à distância (conteúdos e carga-horária) da } \\
\text { disciplina podem ser avaliadas como? }\end{array}$ & $\begin{array}{l}\text { (5) ótima, (4) boa, (3) } \\
\text { regular, (2) ruim, (1) } \\
\text { péssima }\end{array}$ \\
\hline & $\begin{array}{l}\text { PP5- A prática didático-pedagógica desenvolvida nos mo- } \\
\text { mentos presenciais pode ser avaliada como? }\end{array}$ & $\begin{array}{l}\text { (5) ótima, (4) boa, (3) } \\
\text { regular, (2) ruim, (1) } \\
\text { péssima }\end{array}$ \\
\hline & $\begin{array}{l}\text { PP6- O nível de flexibilização da aprendizagem dos alunos } \\
\text { em relação ao tempo e ao espaço durante o desenvolvi- } \\
\text { mento da disciplina pode ser avaliado como? }\end{array}$ & $\begin{array}{l}\text { (5) ótimo, (4) bom, (3) } \\
\text { regular, (2) ruim, (1) } \\
\text { péssimo }\end{array}$ \\
\hline & $\begin{array}{l}\text { PP7- A avaliação da aprendizagem desenvolvida na disci- } \\
\text { plina pode ser avaliada como? }\end{array}$ & $\begin{array}{l}\text { (5) ótima, (4) boa, (3) } \\
\text { regular, (2) ruim, (1) } \\
\text { péssima }\end{array}$ \\
\hline \multirow{3}{*}{ Resultados } & $\begin{array}{l}\text { RP1- A aprendizagem e o aproveitamento dos alunos na } \\
\text { disciplina podem ser avaliados como? }\end{array}$ & $\begin{array}{l}\text { (5) ótima, (4) boa, (3) } \\
\text { regular, (2) ruim, (1) } \\
\text { péssima }\end{array}$ \\
\hline & $\begin{array}{l}\text { RP2- A aquisição de habilidades no uso de computador } \\
\text { pelos alunos durante o desenvolvimento da disciplina pode } \\
\text { ser avaliada como? }\end{array}$ & $\begin{array}{l}\text { (5) ótima, (4) boa, (3) } \\
\text { regular, (2) ruim, (1) } \\
\text { péssima }\end{array}$ \\
\hline & $\begin{array}{l}\text { RP3- O desenvolvimento de autonomia e de auto-organiza- } \\
\text { caão (tempo) pelos alunos durante o transcorrer da disciplina } \\
\text { podem ser avaliados como? }\end{array}$ & $\begin{array}{l}\text { (5) ótimo, (4) bom, (3) } \\
\text { regular, (2) ruim, (1) } \\
\text { péssimo }\end{array}$ \\
\hline
\end{tabular}


Tabela 6. Instrumento para Pessoal de suporte

\begin{tabular}{|c|c|c|}
\hline \multirow{4}{*}{ Entradas } & $\begin{array}{l}\text { ES1- A infra-estrutura de EaD (ambiente/software de } \\
\text { aprendizagem, recursos de videoconferência etc.) disponi- } \\
\text { bilizada pela instituição para a disciplina pode ser avaliada } \\
\text { como? }\end{array}$ & $\begin{array}{l}\text { (5) ótima } \\
\text { (4) boa } \\
\text { (3) regular } \\
\text { (2) ruim } \\
\text { (1) péssima }\end{array}$ \\
\hline & $\begin{array}{l}\text { ES2- As habilidades e competências do professor e dos } \\
\text { tutores para desenvolvimento da disciplina semipresencial } \\
\text { podem ser avaliadas como? }\end{array}$ & $\begin{array}{l}\text { (5) ótimas } \\
\text { (4) boas } \\
\text { (3) regulares } \\
\text { (2) ruins } \\
\text { (1) péssimas }\end{array}$ \\
\hline & $\begin{array}{l}\text { ES3- As habilidades de uso de computador dos alunos } \\
\text { antes do início da disciplina podem ser avaliadas como? }\end{array}$ & $\begin{array}{l}\text { (5) ótimas } \\
\text { (4) boas } \\
\text { (3) regulares } \\
\text { (2) ruins } \\
\text { (1) péssimas }\end{array}$ \\
\hline & $\begin{array}{l}\text { ES4- O planejamento (plano de ensino, c/h EaD, mate- } \\
\text { rial didático, bibliografia, mídias etc.) realizado pelo(a) } \\
\text { professor(a) para a disciplina pode ser avaliado como? }\end{array}$ & $\begin{array}{l}\text { (5) ótimo } \\
\text { (4) bom } \\
\text { (3) regular } \\
\text { (2) ruim } \\
\text { (1) péssimo }\end{array}$ \\
\hline \multirow{4}{*}{ Processo } & $\begin{array}{l}\text { PS1- A interação dialógica desenvolvida entre professor- } \\
\text { tutor-aluno durante a disciplina pode ser avaliada como? }\end{array}$ & $\begin{array}{l}\text { (5) ótima } \\
\text { (4) boa } \\
\text { (3) regular } \\
\text { (2) ruim } \\
\text { (1) péssima }\end{array}$ \\
\hline & $\begin{array}{l}\text { PS2- A tutoria prestada aos alunos durante o desenvolvi- } \\
\text { mento da disciplina pode ser avaliada como? }\end{array}$ & $\begin{array}{l}\text { (5) ótima } \\
\text { (4) boa } \\
\text { (3) regular } \\
\text { (2) ruim } \\
\text { (1) péssima }\end{array}$ \\
\hline & $\begin{array}{l}\text { PS3- O suporte técnico prestado aos alunos durante o } \\
\text { desenvolvimento da disciplina pode ser avaliado como? }\end{array}$ & $\begin{array}{l}\text { (5) ótimo } \\
\text { (4) bom } \\
\text { (3) regular } \\
\text { (2) ruim } \\
\text { (1) péssimo }\end{array}$ \\
\hline & $\begin{array}{l}\text { PS6- O nível de flexibilização da aprendizagem dos alunos } \\
\text { em relação ao tempo e ao espaço durante o desenvolvi- } \\
\text { mento da disciplina pode ser avaliado como? }\end{array}$ & $\begin{array}{l}\text { (5) ótima } \\
\text { (4) boa } \\
\text { (3) regular } \\
\text { (2) ruim } \\
\text { (1) péssima }\end{array}$ \\
\hline
\end{tabular}




\section{CONCLUSÃO}

Os instrumentos elaborados neste trabalho, muito provavelmente, são a primeira proposta para a avaliação específica de disciplinas semipresenciais no contexto da educação superior brasileira. Assim como as demais modalidades educacionais, a semipresencialidade necessita possuir sistemas de avaliação próprios com vistas à melhoria da qualidade. Entretanto, aplicar instrumentos prontos de outras modalidades não parece adequado devido às particularidades da modalidade. Aproveitar o conhecimento existente em modelos reconhecidos e configurá-los no contexto da modalidade semipresencial é mais adequado.

Nesse sentido, o presente trabalho, com base num conceito de qualidade para educação e nos modelos de sistema de indicadores sistêmicos estruturado em aspectos de entrada, de processo e de resultados, desenvolveu uma proposta de instrumentos para avaliar a qualidade de disciplinas semipresenciais.

Os indicadores propostos não se limitam a verificar se os objetivos das disciplinas foram alcançados. Ao permitir o cotejamento entre os indicadores de resultados e os aspectos de entradas e processo da disciplina e entre a avaliação de um sujeito interessado e a autoavaliação de outros sujeitos envolvidos, o instrumento também incorpora aspectos de auto-validação.

\section{REFERÊNCIAS}

ABRAEAD 2008. Anuário Brasileiro Estatístico de Educação Aberta e a Distância. São Paulo: Instituto Monitor, 2008.

BERTOLIN, J. C. G. Avaliação da qualidade do sistema de educação superior brasileiro em tempos de mercantilização - Período 1994-2003. 2007. Tese (Doutorado em Educação) - Universidade Federal do Rio Grande do Sul, Porto Alegre, 2007.

DE MARCHI, A. C. B.; ARAÚJO, D. D. D; STREIT, I. R. Disciplinas semipresenciais em cursos de graduação: relato de experiência da UPF. In: SIMPÓSIO BRASILEIRO DE INFORMÁTICA NA EDUCAÇÃO, 2008, Fortaleza. Anais... Fortaleza, 2008.

ESTRADA, L. R. G. Hacia un modelo de evaluación de la calidad de instituciones de educación superior. Revista Iberoamericana de Educación, Madrid, n. 21, p. 93-103, dez. 1999. 


\section{EUROPEAN COMMISSION. European Report on Quality of}

School Education. Sixteen quality indicators. Luxembourg: European Communities, 2001.

GARCÍA, M. G. Evaluación y Calidad de los Sistemas Educativos. In: RAMÍREZ, Teresa G. (Org.). Evaluación y gestión de la calidad educativa. Málaga: Ediciones Aljibe, 2000.

INEP/MEC. Na Medida - Boletim de Estudos Educacionais do Inep. Disponível em: $<$ http://www.inep.gov.br/download/na_medida/BNMedidaano1-N2-1Jul2009.pdf > . Acesso em: 10 mar. 2010.

MIZIKACI, Fatma. A systems approach to program evaluation model for quality in higher education. Quality Assurance Education, Massachusetts, v. 14, n. 1, p. 37-53, 2006.

NAVARRA. Sistema de indicadores de la educación de Navarra 2003. Navarra: Gobierno de Navarra, 2004.

OECD - ORGANISATION ECONOMIC CO-OPERATION AND DEVELOPMENT. Education at a glance: OECD indicators 2002. Paris: OECD, 2002.

SAHNEY, S.; BANWET, D. K.; KARUNES S. Conceptualizing total quality management in higher education. The TQM Magazine, Bingley, v. 16, n. 2, p. 145-159, 2004.

UNESCO - UNITED NATIONS EDUCATIONAL, SCIENTIFIC AND CULTURAL ORGANIZATION. Marco conceptual. Documentos Laboratorio Latinoamericano de Evaluación de la calidad de la educación. Santiago, Chile: Lecce, Orealc/Unesco, 1997.

VALCHEVA, Donika; TODOROVA, Margarita. Defining a system of indicators for evaluation the effectiveness of e-learning. CompSysTech, 2005. Disponível em: <http://ecet.ecs.ru.acad.bg/cst05/Docs/cp/sV/V.14.pdf >. Acesso em: 11 mar. 2010. 